\title{
O ENGENHO DO INDELIMITÁVEL: HISTÓRIA \\ E TEORIA(S) DOS GÊNEROS LITERÁRIOS FANTÁSTICO E NEOFANTÁSTICO ${ }^{1}$
}

\author{
The wit of the undelimitable: Fantastic and Neofantastic \\ Literary Genres' History and Theory(ies)
}

\author{
Amanda BERCHEZ \\ Universidade Federal de Alfenas \\ amanda.berchez@unifal-mg.edu.br \\ https://orcid.org/0000-0002-2137-8024
}

\begin{abstract}
RESUMO: Neste artigo, o leitor se deparará, in nuce, com um trabalho de revisão, de natureza bibliográfica, da história e da(s) teoria(s) das literaturas fantástica e neofantástica, o que, no que diz respeito, principalmente, ao prisma teórico, é feito a partir da mobilização de certos operadores conceituais, ao exemplo do sobrenatural e sua contraposição ao natural, que se manifestam em notórias reflexões de especialistas das mais variadas áreas, tais como a literário-artística de Nodier e Maupassant, a psicológica de Freud, a filosófica de Sartre, a literário-história de Vax e Schneider, assim como a literário-teórica de Todorov, Noël, Bessière. Nosso principal propósito é recuperar o que, nesta linha epistemológica do fantástico ao neofantástico, for distintivo em se tratando das perspectivas dentre os mais conceituados pensadores que já se debruçaram sobre essas mesmas matérias, trazendo, por exemplo, tanto questões, expoentes, títulos etc. nomeadamente a eles pertinentes quanto, respaldando-nos em argumentos técnico-metodológicos, também leis, máximas, preceitos, princípios etc. que, segundo cada uma dessas perspectivas, os determinam enquanto gêneros literários.
\end{abstract} PALAVRAS-CHAVE: Literatura fantástica; Literatura neofantástica; História literária; Teoria literária.

ABSTRACT: In this article, the reader will be faced, in nuce, with a review work, from a bibliographical approach, of the fantastic and the neofantastic literatures' history and theory(ies), what, regarding,

\footnotetext{
${ }^{1}$ Este artigo é resultado de minha dissertação de mestrado, de título Murilo Rubião, leitor (2020), que foi desenvolvida no Departamento de Teoria e História Literária do Instituto de Estudos da Linguagem (IEL) da Universidade Estadual de Campinas (UNICAMP). O trabalho completo encontra-se disponível em: http://repositorio.unicamp.br/jspui/handle/REPOSIP/338318. Acesso em $13 / 02 / 2021$.
}

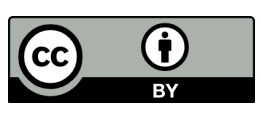


mainly, to the theoretical prism, is made by the mobilization of certain conceptual operators, such as the supernatural and its opposition to the natural, which are perceived in notorious reflections by specialists from the most varied areas, such as Nodier's and Maupassant's literary-artistic ones, Freud's psychological one, Sartre's philosophical one, Vax's and Schneider's literary-historical ones, as well as Todorov's, Noël's, Bessière's. literary-theoretical ones. Our main purpose is categorizing what, in this epistemological line that goes from the fantastic to the neofantastic, is distinctive when it comes to the perspectives of the most respected thinkers who have already dealt with these same matters, bringing, for example, both issues, exponents, titles etc. namely pertinent to them but also, based on technical-methodological arguments, laws, maxims, precepts, principles etc. which, according to each one of these perspectives, determine them as literary genres. KEYWORDS: Fantastic literature; Neofantastic literature; Literary History; Literary theory.

\section{INTRODUÇÃO}

A história das literaturas fantástica e neofantástica já acumula mais de 200 anos, tendo nascido no século XVIII com o Romantismo europeu. Desde Jacques Cazotte, amiúde reputado como precursor da literatura fantástica por Le diable amoureux, publicado na França em 1772, são muitas manifestações marcadas, similarmente a tal romance, pelos gestos simultâneos do pacto e da rescisão com as ordens do real e do sobrenatural. E, como as próprias obras, o aparato histórico, teórico e crítico que se ocupa do fantástico e do neofantástico enquanto gêneros literários é deveras plural, repercutindo a oscilação de natureza tanto teórico-metodológica quanto terminológica que ocorre em função de eles compartilharem traços, por exemplo, com o gótico e o realismo mágico (CAMARANI, 2014).

Feitas essas considerações embrionárias, pretendemos, neste momento, resgatar, pela perspectiva histórico-literária, o que for distintivo das visões de alguns entre os mais conceituados críticos e teóricos, do fantástico ao neofantástico, trazendo leis, máximas, princípios etc. que, segundo cada uma delas, os determinam enquanto gêneros literários, assim como os principais expoentes fantásticos, os devidos títulos literários e um pouco da história dos gêneros. "La definición de una forma literaria busca facilitar el estudio de esa forma, comprender sus posibilidades y límites y distinguir su función y funcionamiento de formas semejantes.", já bem dizia Alazraki (1990, p. 22). 


\section{PRELÚDIOS}

"No puede ser, pero es."

\section{J. L . BORGES}

Ora, se o título de precursor do fantástico está reservado para Cazotte na França, o está para E. T. A. Hoffmann na Alemanha (CASTEX, 1951). E é a tradução para o francês de Phantasiestücke in Callot's Manier, obra de Hoffmann publicada em 1813, o que faz com que o adjetivo alemão "phantastisch", que, noutro tempo, costumava se relacionar à esfera da fantasia ou do imaginário, se torne um termo para designar um gênero literário deveras estabelecido. Inclusive, conforme Schneider (1964), a expressão "contos fantásticos" - mostrando-nos que formal e temático sempre estiveram lado a lado - é empregada justamente a fim de definir a estranheza produzida pela obra hoffmanniana. Daí em diante, a utilização e o alcance do termo "fantástico" vão sendo ampliados, ainda mais devido à contribuição daqueles empenhados na inteligibilidade do gênero, que, desde Hoffmann, está bastante em voga, ainda que tenha sofrido reações adversas ao ingressar no âmbito da literatura. Depois desta breve introdução relativa à adoção do termo, resta-nos, agora, seguir às principais tentativas de teorização sobre o fantástico de que acabamos de falar.

\section{NODIER E A MENTIRA}

As primeiras reflexões teóricas acerca da literatura fantástica de que temos conhecimento constam no ensaio "Du fantastique en littérature", publicado em 1830, do autor e crítico francês Charles Nodier, o qual, passando por Homero e por Hoffmann, faz uma espécie de história literária das manifestações, até então, conhecidas no intuito de intuir sobre o fantástico. Seu raciocínio parte de que a poesia primitiva é o modo de expressão da imaginação do homem, quando na tentativa de descrever e representar o mundo material por intermédio das sensações. Porém, a partir do momento em que a impressão sensorial se desgasta e se modifica por efeito de um longo hábito, em que a materialidade do mundo passa a não mais ser suficiente, enfim, em que o trabalho da poesia primitiva se finaliza no plano terrestre, fazendo por deixar apenas desamparo e prosaísmo, a literatura puramente humana se cerra na vida positiva, sendo organizada conforme os preceitos das ciências contemplativas, da religião e da legislação. Assim, 
o homem racional é cada vez mais centralizado na ordem universal, o que, momentos depois, passa a também não ser suficiente, considerando a existência de toda uma série de situações e de sensações que não consegue explicar na vida cotidiana. A vontade do homem de expandir o conhecimento faz com que o propósito se desvie do conhecido para o desconhecido, surgindo daí, de acordo com Nodier (1830), a mentira, produto da imaginação, a qual outorga espaço para o mundo fantástico, regido segundo as mesmas leis - embora hiperbolizadas - do mundo positivo. Logo, Nodier (1830) constata, ainda mais por ter estado abrangido e ter podido contemplar o contexto romântico europeu, que o fantástico resulta, uma vez efetuadas todas as etapas indicadas acima, do próprio desenvolvimento do espírito humano. Ou seja, não podemos dizer que o fantástico se traduza no estabelecimento de outras ordens, de outros mundos ou de outras leis, mas, sim, no conflito de ordens, de mundos e de leis já existentes, o que faz da realidade um ponto crucial para entendermos, com efeito, o fantástico.

Em seguida, Nodier continua a publicar com vistas não só à sistematização, como também à reflexão sobre os contextos de produção e recepção do fantástico. No segundo prefácio de Smarra ou les démons de la nuit, datado de 1832, ele chega a insinuar que o fantástico, incorporado tanto à literatura quanto à sociedade, é a nova maneira de expressar a sensibilidade das civilizações cujos mecanismos se acham desgastados: "j'étais seul, dans ma jeunesse, à pressentir l'infaillible avènement d'une littérature nouvelle" (1832, pp. 7-8). Já em Histoire d'Hélène Gillet, obra publicada também em 1832, Nodier faz por elaborar toda uma teoria sobre o gênero, elencando os padrões de histórias fantásticas seguintes: a falsa, em que o encanto é resultante da credulidade simultânea de autor e público, como nos contos de fada de Charles Perrault; a vaga, em que a alma é suspensa tal como em um sonho melancólico; e a verdadeira ${ }^{2}$, primeira de todas, em que um fenômeno estranho e materialmente impossível de realização acaba se tornando possível, abalando o coração sem cobrar sacrifícios da razão. O mérito de Nodier é ter, sem dúvidas, dado os passos iniciais rumo às reflexões teóricas acerca do fantástico, esforçando-se por entender o gênero literário em questão. Para encerrarmos, falta ressaltar que, para ele, a apreciação do gênero "exige plus de bon sens et d'art qu'on ne l'imagine ordinairement"' (1832, p. 338).

\footnotetext{
${ }^{2}$ O tipo "l'histoire fantastique vraie" elencado por Nodier corresponde ao fantástico como este passou a ser percebido após Todorov.
}

Revista X, v. 16, n. 3, p. 903-927, 2021. 


\section{MAUPASSANT E A LOUCURA}

Outro autor e crítico francês que traz valiosas reflexões sobre o fantástico é Guy de Maupassant. As primeiras delas estão em Madame Hermet, obra publicada em 1887, em que o fantástico parece estar restrito, mais uma vez, àquilo que é inerente ao humano, não sobrando espaço, por exemplo, para criaturas monstruosas: “l'impossible n'existe plus, l'invraisemblable disparaît, le féerique devient constant et le surnaturel familier" (MAUPASSANT, 1902, p. 253). No entanto, o que se destaca com relação ao homem é justamente a parcela de loucura que lhe é própria, permitindo que a existência prossiga fora de todas prescrições que costumam governar e ordenar as coisas, os pensamentos etc. da vida concreto-material. A lógica, a razão e o bom senso, para ele, “[...] se brisent, s'abattent, s'écroulent devant leur imagination lâchée en liberté, échappée dans le pays illimité de la fantaisie, et qui va par bonds fabuleux sans que rien l'arrête." (MAUPASSANT, 1902, pp. 253-254).

Há as crônicas maupassantianas, voltadas à defesa, mediante discurso mais racionalista, do fim do fantástico no século XIX. Em “Adieu mystères", de 1881, o autor expõe que os adventos do positivismo e da industrialização são as razões pelas quais os espíritos, os fantasmas, enfim, tudo o que antes já foi um mistério não possa mais ser sentido pelo homem de seu tempo, pois há sempre uma explicação de ordem natural ou científica para quaisquer fenômenos fantásticos. Já em "Le fantastique", de 1883, ele continua a defender que a evolução da civilização humana contribui para a derrocada do fantástico, contudo, daquele fantástico fundamentado nas crenças ancestrais, que, um dia, já serviram para elucidar o desconhecido, na forma fosse do impossível, fosse do sobrenatural, fosse do inexplicável, fosse do irreal.

Uma modalidade de literatura fantástica mais sutil é localizada por Maupassant (1883) nas obras de Hoffmann e Poe, que ficam à beira do possível, rondam o impossível ao invés de penetrá-lo, donde permanecem a hesitação, a dúvida quanto aos elementos inexplicáveis e quase impossíveis. Já sobre o leitor, ele coloca que, indeciso, "ne savait plus, [...] se raccrochait brusquement au réel pour s'enfoncer encore tout aussitôt, et se débattre de nouveau dans une confusion pénible et enfiévrante comme un cauchemar". Noutras palavras, por fim, Maupassant rumina não somente sobre as condições de existência do fantástico in fin-de-siècle, como também sobre as condições de produção do autor e de recepção do leitor. 


\section{FREUD E O INQUIETANTE}

A questão do estranho, elemento de presença acentuada, por exemplo, nas obras de Hoffmann, é perscrutada por Sigmund Freud no ensaio "Das unheimlich", de 1919. Em diversos pontos, a discussão travada recorre à literatura para fins tanto de ilustração quanto de prova, tendo início no argumento de que a estética se trata da teoria das qualidades do nosso sentir, donde está incluso mais do que somente o que é tido como belo. É este o caso do que é unheimlich, termo alemão que pode ser entendido como inquietante e relacionado com o que é, ao mesmo tempo, conhecido e familiar, como também com sentimentos de angústia, horror e terror.

Depois de fazer uma extensa análise etimológica do termo e trazer uma reflexão de Ernst Jentsch de que a sensibilidade quanto ao inquietante varia conforme cada indivíduo, Freud (2010) estipula o unheimlich com auxílio da esfera literária, isto é, nomeadamente da obra Der sandmann de Hoffmann. Inclusive, este autor alemão é considerado, por ambos, Jentsch e Freud, como o que mais consegue produzir efeitos inquietantes na literatura; e talvez o consiga porque:

[...] a transposé le merveilleux dans l'âme humaine [...]; il a découvert, aux limites des choses visibles et sur la lisière de l'univers réel, un coin obscur, mystérieux et jusque-là inaperçu; il a suggéré, pour rendre compte des phénomènes qui nous surprennent, des explications déconcertantes pour la science positive et cependant plausibles [...]. (CASTEX, 1994, p. 52)

A princípio, existe, nessa obra hoffmanniana, uma espécie de incerteza que faz, propositalmente, o leitor se questionar se está diante do mundo real ou de um inteiramente irreal, sensação que pode desaparecer durante a trama, pois o autor o autor pode ter manejado para que real e fantástico ocorressem juntos. Para Jentsch (apud FREUD, 2010), tal incerteza é de ordem intelectual e recai na personagem de Olímpia, que pode ser tanto um ser humano quanto um autômato, justamente onde o efeito de estranheza é produzido, ainda mais pelo fato de o leitor não ser levado a se decidir completamente por uma ou outra opção.

No entanto, para Freud (2010), o elemento que mais colabora com a instauração do efeito inquietante está longe de se localizar em tal boneca. O homem de areia, cujo ofício é o de arrancar os olhos das crianças, interessa-lhe muito mais em termos de estranheza, em particular, por ser a prova de que não se trata de um produto da imaginação ou da loucura do protagonista Natanael, o que também vai na direção oposta 
à das considerações teóricas de Nodier e Maupassant. A personagem do homem de areia, à qual se vinculam a de Coppelius e a de Coppola, é capaz de deixar claro que não é o caso, como o queria Jentsch (apud FREUD, 2010), de uma incerteza intelectual, além de que essa tese em nada coopera, entende Freud (2010), para a compreensão do efeito inquietante. O medo de lesionar os olhos representa o medo da castração; dito isso, várias questões de Der sandmann são melhor compreendidas quando comutamos o homem de areia pelo pai - figura à qual diz respeito a castração - do protagonista, ao exemplo da morte deste na narrativa. $\mathrm{O}$ efeito inquietante, deveras empregado no fantástico, também pode se dar quando há a transposição das crenças animistas superadas, como o duplo, a magia, a relação com a morte e o retorno ao mesmo, para a literatura.

Com respaldo também na literatura de Hoffmann, Freud (2010) desenvolve sua própria concepção de narrativa de fantasia. Uma das primeiras considerações que faz é a de que, na literatura, "[...] não é inquietante muita coisa que o seria se ocorresse na vida real, e que nela existem, para obter efeitos inquietantes, muitas possibilidades que não se acham na vida" (2010, pp. 371-372), até porque o reino da fantasia não se faz sujeito a quaisquer validações da realidade. Entre os tipos de narrativa de fantasia, que se distinguem pelo grau de distância em relação à realidade (que, para nós, é familiar), está o que diz respeito, por exemplo, às obras de Hoffmann, que apresentam a realidade cotidiana comum - apesar de poder facilmente ultrapassá-la, pois costumam tratar de episódios com poucas ou nenhuma chance de se consumar em realidade concretomaterial - e trazem, para a literatura, o inquietante das vivências, decorrente tanto dos complexos infantis reprimidos quanto das crenças antigas superadas. Freud (2010) comenta que o leitor reage a esse tipo de ficção como o faria em se tratando das próprias vivências. Ainda com relação ao leitor, algo curioso é que pode restar, ao fim da leitura dessas ficções, a sensação de desgosto, de insatisfação, como se o autor, conta Freud (2010), não tivesse obtido completo êxito ao caminhar, ao mesmo tempo, pelos planos do real e do irreal.

As reflexões de Freud (2010) acerca do inquietante, voltando-se para a área psicanalítica, porém, passeando pelo território do fantástico literário, podem ajudar a compreender melhor a ipseidade desse gênero, sem contar que servem de base para outras teorias, ao exemplo da de Louis Vax (1963), que identifica a íntima correspondência, em produções como as de Maupassant e Hoffmann, entre os temas dos delírios e da literatura fantástica. No mais, é mérito da psicanálise ter conseguido mostrar que, em geral, a arte fantástica deve ser encarada de modo sério, já que, assim como os sonhos, apresenta transposições de imagens intercaladas por profundas e significativas preocupações. 


\section{SARTRE E OS MEIOS}

Outra análise indispensável da literatura fantástica se encontra no ensaio "Aminadab ou du fantastique considéré comme un langage" de Jean-Paul Sartre, publicado em 1947. Para fazer um balanço do fantástico, Sartre (2005) se vale principalmente das obras de Maurice Blanchot e Franz Kafka, na comparação das quais percebe o mesmo estilo acurado e cortês, as mesmas discussões exaustivas e inúteis, as mesmas procuras estéreis e vãs.

Escapar das condições da existência humana consiste em um dos desígnios mais antigos do homem. O ascetismo, o misticismo, a metafísica e a poesia são alguns dos exemplos que Sartre (2005) utiliza para ilustrar o esforço do homem de criar e se esquivar para outros mundos. Transcender o estatuto humano é o propósito que faz, por muito tempo, com que o fantástico seja invocado, o que dá vez a objetos que apenas existem e referem(-se) a si mesmos. Na literatura, o retorno ao homem começa a se dar no período pós-guerra, quando a nova geração de autores, entre os quais Sartre (2005) localiza Blanchot, passa a não mais acreditar na possibilidade de transcendência. E, para poder se combinar ao novo humanismo, o fantástico abandona a exploração do transcendental e se resigna ao tratamento do humano, despojando-se de convenções e artifícios ultrapassados, como fadas, fantasmas e gênios. De acordo com Sartre (2005), o homem contemporâneo encontra no fantástico uma maneira de espelhar a própria imagem, razão pela qual se configura como objeto fantástico por excelência.

Qualidades mais intrínsecas do gênero literário em questão são assinaladas também no ensaio sartreano. Uma delas é a de que o fantástico repudia a imposição de limites, daí é que ou existe por completo ou simplesmente não existe. Para alcançá-lo, não é suficiente nem necessário retratar o extraordinário, não é necessário recorrer às fadas; o fantástico está, por outro lado, no fato de a natureza obedecer às fadas, está na própria natureza, inclusive, dentro e fora do homem. $\mathrm{O}$ universo de todo fantástico é aquele presidido por uma ordem atormentada, que corrói os elos do mecanismo, sem conseguir se expressar devidamente. À vista disso, tudo o que concerne ao fantástico está permeado por aflição, angústia.

O mais significativo, para nós, do ensaio sartreano é a declaração de que o fantástico consiste na revolta dos meios contra os fins. As leis que regem o fantástico o condenam a apresentar somente instrumentos e meios cujas finalidades, disparatadas, nunca consistem, na prática, em servir. Está aí uma das justificativas para a presença, nas narrativas fantásticas, por exemplo, de escadas que a nada levam, filas que nada 
alcançam e signos que nada significam. Um objeto fantástico pode ou ser um meio ou se reportar a outros meios, contudo, não pode chegar a um fim último, que, apesar de ausente, ainda assombra. Não é que não possa existir um fim, é que, quando o assunto é o fantástico, o fim acaba sendo gradualmente consumido pelos meios, que só visam ao próprio bem.

Aliás, é neste ponto que o fantástico se difere do absurdo, já que este representa a total ausência de fins. Tornam-se mais evidentes os porquês de existirem tantos homens que não passam de instrumentos e meios nas obras de Blanchot e Kafka: são funcionários públicos, soldados, juízes, empregados, quer dizer, personagens que fazem com que o universo fantástico mais pareça uma burocracia ou uma sociedade confusa. Até a lei, da qual ninguém pode escapar, é sem propósito, sem sentido e sem conteúdo. Também nada à toa que o fantástico esteja lotado de atividades assediantes, febris, ininteligíveis.

Mais um tópico bastante frisado é a posição ocupada pelo leitor quando de face ao fantástico. Sendo impossível entrar no fantástico sem abraçá-lo por completo, o leitor, ainda que plenamente amadurecido e desperto no seio da civilização, deve se entregar às suas configurações, donde a integração, caso aconteça, se o dê em termos absolutos. Considerando que o acesso ao fantástico ocorre por intermédio do herói, é preciso que o leitor assuma um ponto de vista que não é seu, que dê continuação aos raciocínios iniciados. Feito isso, passará a contemplar tudo sem surpresa, mas também sem compreender, na íntegra, aquilo que o apanha, pois, uma vez dentro do universo fantástico, já não é mais capaz de julgá-lo, já não sabe mais o que sabe. Não esqueçamos de que não há meios-termos quando se trata do fantástico.

Há como que uma existência marginal do fantástico: olhe-o de frente, tente exprimir seu sentido por palavras e ele se desvanece, pois afinal é preciso estar dentro ou fora. Mas se você ler a história sem tentar traduzi-la ele o assaltará pelos flancos. (SARTRE, 2005, p. 146, grifo nosso)

\section{VAX E O ESCÂNDALO}

A obra L'art et la littérature fantastiques de Louis Vax, publicada em 1960, da qual já vínhamos falando por causa da relação entre literatura fantástica e psicanálise, é considerada, até hoje, como uma das mais importantes sobre o referido gênero. No que é da alçada literária, ele procura realçar os traços do fantástico pelo contraste seja com outros campos, como a psicanálise e o ocultismo, seja com outros gêneros, como os romances góticos e os contos de fada. Uma das primeiras considerações é a de que a 
narrativa fantástica "[...] aime nous présenter, habitant le monde réel où nous sommes, des hommes come nous, placés soundainement en présence de l'inexplicable. [...] le fantastique se nourrit des conflits du réel et du possible." (VAX, 1963, p. 6).

No romance gótico, são comuns, por exemplo, castelos encantados, urdidos com elementos extremamente perturbadores, que estão mais ligados, todavia, ao medo do que à realidade, na medida em que são tidos como imaginários e, por conseguinte, irreais. Assim, não há nada de desconfortável na realidade em si mesma, pois o que é imaginário não pode apresentar ameaças efetivas. Aí é que se difere o fantástico, pois pressupõe a introdução dos terrores imaginários no domínio do real e a irrupção do sobrenatural no domínio do suscetível à razão. Não se trata de outro universo que se coloca frente ao nosso, mas, sim, de nosso próprio universo que, paradoxalmente, se corrompe e se transforma em outro, onde se instalam eventos assustadores, estranhos, inexplicáveis, onde são bestas e monstros seres banais, como nós mesmos. Isso porque o desígnio do fantástico é provocar conflitos entre real e possível, é provocar ameaças e desconfortos, donde esteja necessariamente ligado ao escândalo, mas, em especial, o escândalo da razão.

Invocar o fantástico é invocar o absurdo, o contraditório. E, para fazê-lo, a narração se mostra, seguramente, a expressão mais adequada, diz Vax (1963). Não à toa - em atenção, sobretudo, ao fato de que formal e temático são sempre imbricados - que a maior parte do que é elencado como literatura fantástica esteja na forma de contos, já que um poema, por exemplo, é quase incapaz de atender às demandas do gênero. Quanto ao domínio estético, podemos dizer que, ao fantástico, competem ações como "séduire progressivement les facultés actives et critiques de l'âme" e "laisser le charme s'insinuer dans l'esprit' (VAX, 1963, p. 72). Aliás, a contar do século XVIII, novas formas são criadas a fim de que o fantástico substitua superstições grosseiras por expressões estéticas mais delicadas, mais discretas, para públicos mais refinados, motivo pelo qual o advento do gênero pode ser vislumbrado como o progresso da consciência humana. É só no século XVIII que se dá o verdadeiro desenvolvimento da literatura fantástica, assim como é só no século XX que, de acordo com Vax (1963), ela atinge a perfeição. Está enganado, acrescenta, quem acredita que o fantástico, no curso dos séculos, está reduzido a tratar de um número limitado de temas, frequentemente emparelhados com os arquétipos de Jung. É verdade que vários de seus temas antigos acabam perdendo aquilo que possuíam de angustiante, em razão do que se torna possível tratá-los até com ironia e humor, caso da figura diabólica na obra cazotteana Le diable amoureux. Outros tantos temas, em contrapartida, são concebidos, ao exemplo da regressão, dos distúrbios de 
personalidade e das alterações na causalidade espaço-temporal. Sobre as meditações de Vax (1963), só resta a nós findar deixando evidente que, a despeito de a ciência atuar na direção oposta, a literatura fantástica segue cumprindo aquilo que ele toma por seu maior objetivo: a expressão do mistério das coisas.

\section{SCHNEIDER E O DESCONFORTÁVEL}

Em 1964, Marcel Schneider publica a obra La littérature fantastique in France, ofertando o estudo historiográfico das manifestações literárias do gênero no território francês, ainda que, com frequência, sejam admitidas influências de fontes externas à França, ao exemplo de Hoffmann, Poe e Kafka. Um dos primeiros pontos assinalados é que apenas o fantástico pode satisfazer as aspirações mais recônditas do homem. As feições do fantástico não são confortáveis, tranquilizantes, porque dão forma às ansiedades, aos desejos inconscientes, aos sonhos dos mais diversos homens que se defrontam com a angústia da vida e almejam a salvação. Inclusive, a tenção do fantástico é escrutinar alma e corpo humanos. Daí é que histórias de foguetes espaciais, submarinos, isto é, de maquinários mecânicos e tecnológicos, inventados e controlados por homens, não sejam fantásticas, em se tratando do mais autêntico sentido do termo. Em rigor, somente o que é fabuloso, feérico ou maravilhoso está relacionado com o fantástico; todo o restante lhe é contrário ou distante.

Enquanto gênero literário, o fantástico só se constitui, diz Schneider (1964), a partir das obras de Hoffmann, no século XIX, quando irrompem novas possibilidades de expressão, assimiladas com certa rapidez. Isso porque, já no final do século XVIII, começa a se estabelecer um público mais delicado, mais refinado, que espera por obras literárias capazes de fazer mais do que somente perturbar os nervos, isto é, que espera, finalmente, por tons fantásticos. Jean-Jacques Ampère (apud SCHNEIDER, 1964) é um dos primeiros a sinalizar que todo o aparato de figuras como diabos e espectros, medos longevos, terrores gélidos e lugares-comuns firmados com horror não consegue extrair os mesmos efeitos de outrora. A estratégia adotada pelo fantástico é a de estremecer as almas humanas com o fantasma das superstições populares, o poder do mal, o terror do desconhecido.

Sigamos às considerações tanto históricas quanto teóricas do fantástico. Já entendemos que, em primeira instância, "fantástico" é o predicado capaz de, no século XIX, precisar as obras de Hoffmann, como Die elixiere des teufels e Prinzessin Brambilla. Ao contemplar, em perspectiva, o complexo de obras que vêm de uma onda epidêmica do fantástico, Schneider (1964) percebe que uma das mais importantes atribuições do 
fantástico é dar ênfase às maravilhas do que é interior, colocando o que é chamado de realidade em segundo plano. Ou seja, não há vez para palavras mágicas ou truques que concorram para o "charlatanismo" do realismo. O fantástico é uma dimensão exclusiva e irredutível da alma humana, cuja verdade a razão não pode demonstrar. Arranja em histórias cotidianas e descreve em imagens, símbolos e termos concreto-sensíveis problemas de todos os homens, tais como o amor, o destino, o rosto de Deus, a salvação e o tempo. A parte da existência humana que lhe é de mais interesse é aquela noturna, dos delírios, das forças irracionais, dos presságios, das quimeras, dos sonhos, enfim, dos territórios onde a imaginação sucumbe às irregularidades de seus caprichos. Afinal de contas: "Le sommeil n'est-il pas aussi nécessaire que la veille, le rêve que l'action, la folie que la raison et le désir que l'objet fabriqué?" (SCHNEIDER, 1964, p. 11).

\section{CAILLOIS E O IMPOSSÍVEL}

O prefácio "De la féerie à la science-fiction" de Anthologie du fantastique, obra com a seleção fantástico-literária de Roger Caillois, publicada em 1966, traz contributos teóricos por meio do cotejo do fantástico com os contos de fada e a ficção científica. Embora parelhos quanto aos elementos maravilhosos e sobrenaturais, os referidos gêneros apresentam versões diferentes e impermutáveis de maravilhas e milagres. Retomaremos a parte do percurso feito por Caillois (1966) que diz respeito ao fantástico a fim de que possamos entender aspectos de seu estabelecimento e esclarecer algumas de suas questões.

O que faz fantasmas, por exemplo, competirem ao fantástico, ao passo que duendes e ogros, criaturas não menos sobrenaturais, competem aos contos de fada? $\mathrm{O}$ maravilhoso, do qual se banha a Idade Média, é anterior ao fantástico; este, sabemos, é contemporâneo do Romantismo europeu e começa a se estabelecer, a despeito de raras exceções, no século XVIII. O desponte do fantástico só acontece após o triunfo de uma ordem racional, de um determinismo severo no encadeamento de causas e efeitos, isto é, quando a ciência qualifica milagres e mistérios como inadmissíveis, algo que altera também a condição humana. O fantástico é a consumação do impossível, a ruptura da estabilidade em um universo cujas leis são [tidas como] inexoráveis. Já o sobrenatural aparece como a transgressão da coerência universal, acarretando desamparo e pânico do desconhecido. Ao contrário do que acontece nos contos de fada, há, nas narrativas fantásticas, a irrupção insólita - quase intolerável - do escândalo na própria realidade, o que concorda com as meditações de Vax (1963). Ou seja, é justamente o ingresso no domínio domesticado do real que faz com que fantasmas e vampiros, embora seres da 
imaginação, como duendes e ogros, sejam capazes de amedrontar, ainda mais porque eclodem em momentos dos mais inesperados. Aliás, é graças a tópicos como aparência banal e familiar e percursos repentinos e tortuosos, estes geralmente culminando em desaparição, condenação ou morte do herói, que a atmosfera de horror se instaura nas narrativas fantásticas.

A investida do impossível sobre o cotidiano, este já não mais blindado pelas certezas científicas, pode se dar, segundo Caillois (1966), mediante os seguintes temas fantásticos: almas perdidas; coisas indefiníveis e invisíveis; contraversões dos domínios da realidade e do sonho; maldições dos feiticeiros; mulheres-fantasmas; pactos com os demônios; personificações da morte; animações de armaduras, estátuas, manequins e máquinas; desaparecimento de departamentos, pisos, casas, ruas etc. com relação ao espaço restante; paralisações e repetições do tempo. E, nos casos em que não sucede o escândalo, existem subterfúgios para solucionar o fantástico, como: explicações para o sobrenatural; alucinações, ilusões, sonhos; anomalias, monstruosidades; informações psíquicas emanadas do espiritualismo, da telepatia. É propício incluirmos, por último, que, para esse crítico, a literatura fantástica, além de vir sendo substituída pela ficção científica, se configura como um jogo com o medo e se situa no plano da pura ficção.

\section{TODOROV E A VACILAÇÃO}

Grande parte dos autores e seus respectivos julgamentos sobre o gênero de que tratamos é apontada na obra Introdução à literatura fantástica de Tzvetan Todorov, publicada em 1970. O autor, com o respaldo de uma ampla - em termos tanto literários quanto teóricos - bibliografia, é um dos que mais se ocupam do ofício de descobrir, de fato, o que está regendo o gênero em questão.

Em primeiro lugar, Todorov (2007) declina explanações - ele se refere, por exemplo, às de Castex, Vax e Caillois - que convertem o fantástico em mera substância. Não é só do sobrenatural, ao contrário do que pensam muitos autores, que, para ele, se trata o referido gênero, pois, se assim o fosse, obras como as de Homero e Shakespeare deveriam ser rotuladas como fantásticas. Também não é o caso de fazer da experiência particular de um leitor real, algo como Lovecraft faz com relação ao medo, um critério do fantástico, porque semelhantes sentimentos, apesar de relacionados com o gênero, não chegam, sozinhos, a determiná-lo. Outras tentativas de definir o fantástico, feitas, por exemplo, a partir da posição do autor ou da oposição à realidade, são igualmente dispensadas por Todorov (2007), que, por meio da diferença, delineia, pouco a pouco, o que lhe parece característico do gênero. 
O fantástico se caracteriza pela vacilação que dado ser, por não conhecer mais do que as leis do mundo natural, experimenta ante um fenômeno aparentemente sobrenatural. Outro assunto bastante reiterado durante a argumentação do autor é o caráter evanescente do fantástico, que tem a ver, sobretudo, com a fronteira que o fantástico faz com o estranho e o maravilhoso, seus gêneros vizinhos. Acontece que, caso a vacilação - quanto ao que é real e ao que é ilusório (tratado como uma falha da percepção) ou ao que é imaginário (tratado como um fruto da imaginação) - de que falamos seja resolvida, quer pelas personagens, quer pelos leitores, o fantástico, que se nutre, acima de tudo, da incerteza, deixará de existir. A resolução pode consistir: a) ou na explicação dos fenômenos sobrenaturais a partir de leis conhecidas, provindas da realidade, pelo que se dá, então, o gênero estranho; b) ou na admissão de outras novas leis que consigam explicá-los, pelo que se dá, então, o gênero maravilhoso. "“Cheguei quase a acreditar': eis a fórmula que resume o espírito do fantástico", para fora do qual levam tanto "a fé absoluta" quanto "a incredulidade total" (TODOROV, 2007, p. 36).

Há, no entanto, algumas outras condições para a manifestação do gênero. Uma delas é a identificação do leitor implícito - o que está mais relacionado, segundo Todorov (2007), com uma função de leitor - com as personagens da obra, processo que é favorecido com o emprego da primeira pessoa; isso porque é mais fácil e provável que o leitor se reconheça no narrador, meio mais imediato de penetração no fantástico. Aproveitando o tópico, a combinação entre acontecimentos sobrenaturais e narrador natural é outra condição considerada excelente para que ocorra o fantástico. A identificação entre leitores e personagens depende da temporalidade do processo de enunciação, marcada pelo caráter de irreversibilidade. Em se tratando de fantástico, as convenções de leitura (a saber, da esquerda à direita, de cima para baixo, do início ao fim) são levadas às últimas consequências, pois, se violadas, obstam que o leitor se identifique com a personagem. A primeira leitura se distingue das demais por ser a única por meio da qual se dá a identificação entre leitor e personagens; as outras servem apenas para evidenciar os procedimentos de construção do fantástico. Mais uma condição para o fantástico, cujo universo deve ser encarado em termos reais, é a renúncia aos modos de leitura alegóricos, pelos quais a diferença entre expressão e significação leva à supressão do sobrenatural, como também aos poéticos, pelos quais a literalidade das cadeias linguísticas despreza as possibilidades de representação ou referência, impedindo a presença do sobrenatural. Isso quer dizer que o fantástico só pode acontecer na ficção; a saber, o universo engendrado não possui existência externa à linguagem. 
A análise dos temas fantásticos ganha espaço na obra de Todorov (2007), que abre mão de categorias que não são literárias para descrevê-los, além de procurar identificálos com base no nível abstrato, evitando fazê-lo no nível concreto, isto é, no de imagens. Graças à tentativa de sistematização com maiores níveis de abstração, um dos poucos autores mencionados é Witold Ostrowski, o qual defende que os temas fantásticos equivalem à transgressão de um ou mais itens representados no esquema abaixo:



(OSTROSKI, 1966, p. 57 apud Todorov, 2007, p. 110)

O fantástico possui a função - tanto literária quanto social - de transgredir sistemas de leis e regras já consolidados. Então, fica evidente o porquê de os temas do fantástico tratarem do que é tido como tabu, do que é censurado na e pela sociedade. Contudo, Todorov (2007) diz que a parcela social da função do fantástico é, a partir do século XX, assumida pela teoria psicanalítica freudiana, fazendo com que não seja mais necessário recorrer à figura do diabo para aludir aos desejos sexuais nem à do vampiro para aludir ao interesse por cadáveres, considerando que pode abordar esses mesmos assuntos diretamente. Ele também comenta que a função de suscitar reações vacilantes tanto no herói quanto no leitor só é, de maneira satisfatória, desempenhada pelas obras de Cazotte e Maupassant. A partir do instante em que surgem heróis, como o d'O castelo kafkiano, que são fantásticos, os leitores apenas conseguem cumprir com o quesito de identificação caso abdiquem da esfera do real e se tornem igualmente fantásticos. Ou seja, obras como as de Kafka forjam a generalização do fantástico, pelo que contagiam tudo o que lhes diz respeito, seja interno, como os heróis, seja externo, como os leitores. Os fantásticos engendrados, por exemplo, por Cazotte e Kafka se divergem na medida em que a exceção daquele se converte na regra deste, o que significa que a realidade kafkiana é inteiramente fantástica. Porém, se o real é de todo fantástico, não resta mais espaço para a dúvida, a hesitação, a vacilação. E, sem vacilação, sem fantástico. Logo, finaliza Todorov (2007), a literatura fantástica já não existe entre nós. 


\section{NOËL E A IRREPRESENTAÇÃO}

Discrepando de Todorov (2007) quando na conceitualização do fantástico por não acreditar ser uma profícua exploração de terras já conhecidas, Jean Bellemin-Noël, no artigo "Des formes fantastiques aux thèmes fantasmatiques", publicado em 1971, propõe uma abordagem que, embora mais ingênua, não desrespeita substancialmente procedimentos estruturais. Um dos passos dados por ele em direção a uma definição mais funcional do fantástico é cancelar a noção de estranho enquanto seu balizador conceitual, optando por ressaltar suas propriedades estruturais por meio do cotejo com outras categorias de obras literárias, a saber, o maravilhoso e a ficção científica, as quais designa, por conveniência, como gêneros.

A primeira consideração é a de que a ficção é, genuinamente, urdida para ser lida. A fórmula do fantástico é aquela em que o Narrador $^{3}$ é o próprio herói, algo como que nos termos: "je m'interroge sur ce que je raconte [et] qui m'est arrivé" (NOËL, 1971, p. 109). Mesmo quando quem age e quem conta parecem existir em esferas diferentes, eles não deixam de ser hipóstases da mesma figura, a do narrador-protagonista; ambos - mediante propícios artifícios narrativos: seja companheirismo, seja confidência (lida ou ouvida) privilegiada, seja herança de documentação íntima - dominam os mesmos acontecimentos, compartilham da mesma cultura, comportam-se da mesma maneira, enfim, assemelham-se e complementam-se. O esquema organizacional, em harmonia com Noël (1971, p. 109), é o de uma narrativa, com efeito, racionada: "il y a je - le témoin lucide - qui s'interroge dans l'incertitude, et il y a moi - le héros - qui vit l'aventure avec passion (jusqu'à la mort ou la folie, dans la majorité des cas)". Pelo fato de que os discursos do narrador e do herói costumam vir embaraçados, justapostos, além de até mesmo poder jogar com o tema da divisão, [em outras palavras,] ao considerar que uma mensagem pode ser disseminada por duas vozes, duas maneiras, torna-se nítido e irrefutável que é sobre toda uma técnica contrapontística de composição literária que está assentada a narrativa fantástica.

Existem, no fantástico, dois [tipos de] discursos: aquele do racional, referente à testemunha, à consciência lúcida, que almeja a insígnia de referencial; e aquele do inexplicável, do frenético, do alucinatório, que almeja, por meio da escrita "poética", ser eficaz com o respaldo da coerência estrutural. A "coisa" fantástica, sugerindo a existência

\footnotetext{
${ }^{3}$ Segundo Noël (1971, p. 109), a letra maiúscula para o vocábulo "narrador" diz respeito à objeção de que a pessoa à frente da história não é a protagonista, o que, para o autor, se trata apenas de uma aparência, já que a "vision du dedans" e a "vision avec" nunca se separam nitidamente. 
do inexistente, nunca surge plenamente à luz, nunca pode ser vista em todos os seus ângulos, em todas as suas dimensões. Lovecraft se vale dos motivos, por exemplo, da noite, da chuva, do nevoeiro para o ofício fantástico de dissimular. A insuficiência da visão acaba recrutando a ação de outros sentidos, que passam a se ocupar de correntes de ar, de odores sórdidos, de sussurros suspeitos etc. "C'était comme si", "cela ressemblait à", "on aurait dit une espèce de" (NOËL, 1971, p. 112): analogias, comparações, sugestões se fazem frequentes, donde seja possível falar, no fantástico, de uma "escrita poética".

En fait, la fausseté référentielle de la "chose" la consacre comme objet verbal; son statut est entièrement métaphorique. Il faut savoir [...] offrir un réseau de métaphores tel que, en creux, soit déclaré l'indicible; tel que la présence épaisse des mots masque l'absence des choses en révélant la présence incertaine de ce qui ne peut ni être ni être dit. C'est le triomphe de la rhétorique, dans l'assaut de toutes ses figures. L'art le moins 'représentatif' en littérature est celui qui a le plus besoin des compensations du langage: le non-figuratif est le tout-figuré. A regarder de près la technique employée par les auteurs fantastiques pour donner de la réalité à l'irréel, on pourrait même parler d'une rhétorique de l'indicible. (NOËL, 1971, p. 112, grifo nosso)

O fantástico trabalha com a "insignificação", uma vez que quer expressar conotativa e, não, denotativamente, uma vez que concebe significados curtos, porque associados a inúmeras redes de imagens. Ao processo de nomeação, coaduna-se o de pseudo-preterição, figura retórica do falar-pelo-não-falar, que, no fantástico, toma formas como as que seguem: "Je ne vous dirai pas que...", "Impossible de décrire ce que...", “Je ne puis décrire ce que je vis: cela ressemblait..." (NOËL, 1971, p. 113). Nada é verdadeiramente descrito, apenas transferido. Tendo sido dito que algo não pode ser dito, são arranjados alguns traços metafóricos que como que apresentam, em negativo, aquilo que é impossível de ser descrito. O leitor acredita lidar com um produto que, na verdade, não passa de um engodo. A estrutura do fantástico é contagiante, pois aquilo que pretende mostrar é escondido para the conferir presença máxima, pois aquilo que, mesmo que duvidosamente, é declarado como presente não pode ser colocado como que para ser revelado. Noël (1971) conclui que a dinâmica preteritiva do fantástico alcança um efeito duplo, pois pode acabar confirmando um significado mais profundo da escrita de fantasia. É nisso que, enfim, consiste a retórica do procedimento fantasmagórico, que ele continua a explorar em outro artigo, "Notes sur le fantastique", publicado em 1972. 
Qualquer síntese acerca do que é fantástico, para Nöel (1972), é prematura. Seu primeiro movimento é qualificar como fantasmagórico ${ }^{4}$ o conjunto de processos do gênero fantástico, constituído de histórias para cujos desenrolamentos não somos, enquanto leitores, capazes de dar explicação alguma. O alicerce do fantasmagórico está compreendido na irresolução - à qual Freud 5 (2010) alude por "incerteza intelectual" e Todorov (2007), por "hesitação" -, seja em relação à situação, seja em relação ao leitor. Quando diante do fantástico, o leitor perde o norte, vê-se despojado daquela ingênua fé que, antes, lhe permitiu situar uma origem para as coisas do mundo. Isso porque o fantástico, além de alçar o imaginário ao estatuto do real, põe em perigo e problematiza a convicção de realidade, instituindo subversões em sua condição fictícia. $\mathrm{O}$ autor é incumbido de deixar explícita a assinatura do mistério, seja sinalizando a ambiguidade da situação, seja recorrendo a alusões, referências culturais, quer dizer, algo que seja capaz de produzir um espaço fantástico. Já o objeto ou o instante crucial da aventura é tido como indescritível: "Monstre immontrable; représentation irreprésentable. Néanmoins le récit est contraint de le mettre en scène. Une rhétorique particulière se trouve alors mobilisée pour l'évoquer, le suggérer, imposer sa 'présence'à travers les mots, au-delà d'eux." (NÖ̈L, 1972, p. 5).

A literatura é feita com palavras. A concepção fantástica do nosso próprio mundo, só que com outras palavras, mostra a pertinência do pensamento de Freud, em especial com relação à questão do unheimlich: "le fantastique, c'est l'intime qui fait surface et qui dérange" (NOËL, 1972, p. 23). É a mesma contraposição, diligentemente dosada e engendrada, que possibilita perceber o paradoxo de que são as histórias do delírio, da noite, da fantasia - e, não, as dos extensos romances realistas - que, de fato, melhor conseguem dar a conhecer a profunda e cotidiana realidade, assim como a relação que temos com ela. O fantástico, quando arquiteta um mundo que pensamos ser (como) o real, está, na prática, apenas fingindo ser (como) o real, a fim de que assimilemos, por meio do imaginário, aquele real que costumamos recusar. E é justamente esta, encerra Noël (1972), a maior de suas proezas.

\section{BESSIÈRE E A INCERTEZA}

Para Irène Bessière, em Le récit fantastique: la poetique de l'incertain (1974), o fantástico não pode ser entendido nem como atributo de objetos ou seres nem como

\footnotetext{
${ }^{4}$ Etimologicamente, "l'art de faire venir sur la scène publique des fantômes". (NOËL, 1972, p. 4) ${ }^{5}$ É, todavia, o psiquiatra Ernst Jentsch, como já tivemos a oportunidade de observar, o responsável pelo desenvolvimento da concepção de "incerteza intelectual”, embora Noël (1972) confira tal proeza a Freud.
} 
categoria ou gênero literário, pois, na verdade, consiste em uma lógica narrativa formal e temática que expressa, atrás do jogo com aparência de completa invenção, as variações culturais da razão e do imaginário coletivo. A forma do fantástico é aquela que mistura caso e adivinha, isto é, reivindica uma tomada de decisão, todavia, tolhida já que o objeto tétrico, embora se ofereça à decifração, não pode ser compreendido pelo sujeito, que não pode senão constatar sua presença. $O$ fantástico faz questionamentos tanto culturais quanto históricos sobre o estatuto do homem e da realidade, trazendo a desconstrução de elementos objetivos, principalmente relativos a instituições, como a mitologia, a filosofia, o esoterismo e a religião, que lidam com as crenças humanas. Amparado pela matéria cotidiana do homem deste mundo, engendra outros mundos, em que são confrontados fenômenos que confirmam ou escapam aos arranjos do real e do sobrenatural, fazendo com que as leis que regem o realismo sejam perturbadas. Ultrapassa também as configurações dualistas admitidas nas perspectivas racionais, como naturalidade-sobrenaturalidade e ordem-desordem, levando a contingência do mundo às últimas consequências. Ambíguo, ambivalente e paradoxal, é tido como a organização lúdica que obtém argumentos do que é rejeitado pela razão. Ostentando coerência e nexo próprios, admite a justaposição e, por conseguinte, a contradição de múltiplas verossimilhanças, pelo que consegue provocar a incerteza. Em detrimento da verdade da atuação, prioriza a do acontecimento, o que justifica comportamentos mais passivos das personagens, que, reféns da fatalidade, suportam o máximo sem contestá-lo, no decorrer das sequências narrativas.

O fantástico implica a polivalência. Embora surja do maravilhoso, do qual herda a estampa do sobrenatural, o fantástico pode ser designado como um anti-conto, levando em conta que: em contraste com o dever-ser daquele, revela a flutuação; em contraste com a norma daquele, revela o questionamento sobre a norma; em contraste com a universalidade daquele, revela a singularidade, deixando nítido como cada caso que dá a conhecer é bem específico. No campo literário, enseja histórias marcadas pela admissão de possibilidades incompatíveis com as leis da natureza e da sobrenatureza, pela combinação de espetáculo e ilusão, pela irrealidade intelectual dos argumentos que apresenta. As tentativas de definição do fantástico literário geralmente costumam pecar tanto por limitá-lo a elementos que, mesmo requeridos na narração, não lhe são intrínsecos, como o estranho e o sobrenatural, quanto por interpretá-lo de maneira errônea.

A expressão da experiência imaginária dos extremos que o racional pode alcançar: é nisso que, para Bessière (1974), consiste o fantástico, cuja eficácia, aliás, é praticar, pelo viés do improvável, a arte da imaginação, abrindo margem para situações que recebem a etiqueta de irreais. Insuficientes, no entanto, necessários, os princípios 
da extranaturalidade e da falsidade condicionam o fantástico, o qual, na condição de projeto estético, não pode confessá-los abertamente. Na medida em que extrai tanto seus motivos quanto seus objetos de uma realidade falsa, que reclama uma existência aparente, o fantástico acaba não podendo ser representado. Seu projeto literário, além de antinômico, é tético, isto é, supõe a verdade - sobretudo, cultural - do que exprime. $\mathrm{O}$ fantástico monta o jogo da irrealidade aliada à realidade (ao mesmo tempo, empírica e meta-empírica), que insinua a existência daquilo que, nas disposições da natureza e da sobrenatureza, simplesmente não pode existir. Ele lança mão de uma forma mista de narração, com doses específicas de índices causais e temporais, a fim de alimentar uma motivação realista. Aos temas do fantástico, cabe defender, por meios persuasivos, a matéria falsa, na forma seja da ilusão confessada, seja da verdade dissimulada. Já o cotidiano, por essência, familiar e hierarquizado, assiste à instauração do enigma, bem como à invasão de figuras limítrofes do conhecido, ao exemplo de aparições, diabos e espíritos, que, além de mostrar como rupturas de diversas ordens se tornam possíveis, assustam por revelar que a morte talvez não implique um fim, que a vida talvez não tenha um fim. Não é sobre o compartilhamento de crenças, autênticas ou forjadas, mas, sim, sobre a sensibilidade, sobre a tolerância para o que é incerto, inventado, novo que incide a problemática da recepção do fantástico. Bessière (1974), por fim, afirma que o fantástico é um monstro estético que costura diferentes tipos de narrativas, ao exemplo do conto alegórico, da fábula e do romance, e sonda tanto as verdades dos monstros reais, produzidos pela natureza e pela sociedade, quanto as contradições relacionadas ao modo como eles são apreendidos. Prescindindo de referência ao além, o fantástico dá expressão às fraturas culturais da racionalidade, pelo que utiliza argumentos como o da circularidade, o da falsa progressão, o das sequências de aparições e desaparições, o dos jogos de espelhos, o das duplicações, o das repetições e o das metamorfoses. E é a figuração de como a própria identidade do real pode ser múltipla a questão por meio da qual o fantástico faz as maiores de suas contribuições em termos literários, deixando evidente, ao passo que tanto imita quanto reflete sobre a realidade, que é mais que exímio só na arte do engano, das ilusões, das quimeras.

\section{ALAZRAKI E A DISCRIMINAÇÃO}

Tachar, por falta de predicado melhor, as obras de Kafka, Borges e Cortázar como fantásticas é um feito nada isento de problematizações (sobretudo, teóricas), haja vista o artigo de Jaime Alazraki, “¿Qué es lo neofantástico?”, publicado em 1990. Nele, ao atinar que o modo pelo qual o fantástico foi, até o século XIX, literariamente praticado Revista X, v. 16, n. 3, p. 903-927, 2021. 
e discernido já não dá conta [de muitas] das produções contemporâneas, como as dos autores citados, Alazraki (1990) propõe estipular um novo gênero, capaz de contemplar esse tipo de ficção que, apesar de emanar, devido ao componente fantástico, se difere essencialmente de seus precursores fantásticos, devido à sua visão, à sua intenção e ao seu modus operandi; trata-se do que ele, visando tanto à inteligibilidade do alcance e dos sentidos do novo gênero quanto à aprimoração dos estudos das novas manifestações, cunha "neofantástico".

A visão do neofantástico consiste em fazer dessa realidade que conhecemos um filtro por cujas aberturas seja possível vislumbrar outra realidade. Já a intenção do neofantástico, diferentemente do que acontece no fantástico, não é provocar medo ou temor, a partir de que as resoluções lógicas são abaladas; o é, ao invés disso, provocar, recorrendo ao emprego de metáforas, inquietude e perplexidade, quando ante a inqualificabilidade da conjunção narrada. Em atenção a esses sentidos figurativos, metafóricos, oblíquos do neofantástico é que, de acordo com Alazraki (1990), nenhum ocorrido consegue - pelo menos, não dentro de nossos padrões, enquanto leitores, de compreensibilidade - ser cabalmente compreendido ou explicado. Por último, o modus operandi do neofantástico se caracteriza pela apresentação do fator fantástico desde o início da narrativa, de modo que não se fazem mais necessárias, por exemplo, as rupturas de causalidade, propiciadas pela instituição de quadros similares aos da realidade cotidiana que nós, autores e leitores, dominamos do comércio com a vida.

Vale, enfim, que pontuemos que, enquanto o fantástico tradicional, assim como o movimento romântico, junto do qual surge, coloca em discussão, por exemplo, os princípios do racionalismo científico e da burguesia, o fantástico contemporâneo ou neofantástico - incorpora os efeitos de fenômenos como a psicanálise freudiana, a Primeira Guerra Mundial e os movimentos vanguardistas. E é justamente por acreditar que não é mais exequível paliar as diferenças entre essas categorias - ao mesmo tempo, tão próximas, porque parentes, e tão longínquas, porque diferentes - de fantástico que Alazraki (1990) prontifica a discriminação, de caráter tanto literário quanto históricocontextual e teórico-conceitual, do neofantástico. Afinal, como dizia Harry Levin (apud ALAZRAKI, 1990, p. 31), "[l]as especificidades nos ayudan mucho más que las generalidades". Cortázar (apud ALAZRAKI, 1990, p. 32) sobre essa modalidade contemporânea, com a qual emoldura a própria obra, de fantástico:

Es decir, no es un fantástico fabricado, como el fantástico de la literatura gótica, en que se inventa todo un aparato de fantasmas, de aparecidos, toda una máquina de terror que se opone a las 
leyes naturales, que influye en el destino de los personajes. No, claro, [...] es muy diferente.

\section{ROAS E A AMEAÇA}

De modo a confrontar a argumentação de Alazraki (1990), David Roas, na obra A ameaça do fantástico (2014), afirma que, a partir das obras, por exemplo, de Kafka e outros autores do século XX, é adotada, com efeito, uma nova estratégia para elaborar o fantástico, que se baseia na concepção pós-moderna da incerteza perante a realidade, quer dizer, de ausência de lastros pelos quais seja factível decifrá-la indubitavelmente. É por isso que Roas (2014) endossa, parcialmente, as restrições feitas, por exemplo, por Todorov (2007) quanto à possibilidade de transgressão por parte das obras fantásticas contemporâneas, dado que não há como transgredir uma realidade que não é de todo conhecida ou em que tudo é possível. Ou seja, será sentido como transgressão fantástica tudo o que não couber nos padrões físicos segundo os quais assimilamos o nosso mundo.

O fantástico contemporâneo, para Roas (2014), é marcado pela irrupção da sobrenaturalidade na esfera da realidade, que não visa a frisar o que há de sobrenatural - elemento sem o qual esse gênero, de fato, não opera -, mas, sim, o que há de anormal no real, motivo pelo qual sua estabilidade é assaltada. Ao enfrentar o sobrenatural, que provoca ameaça e não pode ser racionalizado, e comprovar que a realidade fantástica, que pretende passar como a nossa, não funciona como esperado, isto é, como a nossa, o leitor, impressionado e interrogado, perde toda a segurança que tinha com relação às coisas do mundo. Outro distintivo do fantástico contemporâneo, então, é a capacidade de intervenção na noção que temos da realidade.

Se o fantástico não prescinde daquilo que tomamos por realidade, que, por sua vez, não prescinde daquilo que conhecemos, torna-se irrefutável a conexão que o gênero mantém com o contexto extratextual, sobretudo, em termos socioculturais, pois todas as representações da realidade partem de modelos de mundo vigentes em dadas culturas. A atividade do leitor, no fantástico, é crucial, porque um fenômeno só poderá ser encarado como fantástico quando for confrontado com as concepções extratextuais que ele tem do real. Ou seja, o realismo faz-se estruturalmente necessário para as obras fantásticas, as quais, por isso mesmo, demandam, mais do que as de quaisquer outros gêneros, leituras referenciais.

[...] não se pode escrever contos fantásticos sem contar com um quadro de referência que delimite o que é que ocorre ou não ocorre em uma situação histórico-social. Esse quadro de referência está dado ao leitor 
por certas áreas da cultura de sua época e pelo que ele sabe de outros tempos e espaços que não os seus [...]. (BARRENECHEA, 1985, p. 45 apud ROAS, 2014, p. 46)

Mas, mesmo fazendo por arquitetar o real, o fantástico postula a transgressão do código realista ao propor a analogia a uma realidade não só que admite como de que provém o sobrenatural. E já é suficiente para gerar inquietude a simples possibilidade de haver uma transgressão, pois faz com que as leis da realidade fiquem frouxas e sejam pouco confiáveis. Dizendo de outra maneira: o fantástico contemporâneo desdiz os artifícios interpretativos à custa dos quais a humanidade, desde sempre, orientou sua existência, mostrando-lhe, contudo, de um modo diferente de como fazia o fantástico tradicional, a inconsistência dos contornos, cultural e ideologicamente falando, do mundo em que vive.

A aparição do fantástico não tem por que residir na alteração por elementos estranhos de um mundo ordenado pelas leis rigorosas da razão e da ciência. Basta que se produza uma alteração do reconhecível, da ordem ou desordem familiares. Basta a suspeita de que outra ordem secreta (ou outra desordem) possa colocar em perigo a precária estabilidade da nossa visão do mundo. (FERNANDEZ, 2001, pp. 296297 apud ROAS, 2014, p. 71)

O fantástico contemporâneo preserva o projeto que emblemou o tradicional no decorrer de sua história: a sugestão de contradições na realidade. Ainda que, na transição de um para outro, a expressão da transgressão tenha sofrido modificações, a noção do real continua sendo indispensável para que, por meio da confrontação, seja definido o grau de fantasticidade de uma obra. Não é, portanto, a questão de deliberar o fantástico contemporâneo, o neofantástico, como divergente do tradicional, considerando que são muito mais afins do que, à primeira vista, se poderia supor, mas, sim, como estágio seguinte na escala evolutiva do gênero fantástico como um todo, que se calca noutra compreensão acerca do homem e do mundo.

\section{DESATE, CONSIDERAÇÕES FINAIS}

Concluído todo este trabalho de revisão com múltiplas meditações e seus devidos pontos de iluminação, fazendo por aclarar aspectos que, quando contemplados em conjunto, se revelam capazes de distinguir e formar gêneros literários, haja vista o fantástico e o neofantástico, aquilo que, portanto, ficou a nós claro foi que esses são 
compreendidos, sobretudo, pelo assalto do sobrenatural na esfera do natural; e, como efeito disso, se verifica a adoção de posturas transgressivas, assim como de perspectivas moderna e contemporaneamente situadas sobre o homem e o mundo.

Antes de arrematarmos o estudo, devemos, finalmente, deixar acentuado que todas as apreciações, todas as questões de cunho crítico, histórico, teórico etc. delineadas, desde o século XIX, por vários pensadores com relação aos gêneros fantástico e neofantástico, que, aqui, elencamos - longe de nós, no entanto, a pretensão ou a defesa de tê-las esgotado -, mesmo que não consigam dar completamente conta deles, pelo menos contribuem para desatar alguns dos nós que podem vir a se colocar em se tratando das linhas de compreensão e tangibilidade que lhe são inerentes, sem contar que indicam diversos possíveis pontos de contato entre literaturas, como as de Edgar Allan Poe e E. T. A. Hoffmann. E é por tudo isso que acreditamos estar integralmente justificada e validada essa empreitada que, agora, só nos resta findar.

\section{REFERÊNCIAS}

ALAZRAKI, Jaime. ¿Qué es lo neofantástico? Mester, v. 19, 1990, pp. 21-33. Disponível em: escholarship.org/uc/item/7j92c4q3. Acesso em: 22/07/2019.

BELLEMIN-NOËL, Jean. Des formes fantastiques aux thèmes fantasmatiques. Littérature, n. 2, 1971, pp. 103-118.

BELLEMIN-NOËL, Jean. Notes sur le Fantastique (textes de Théophile Gautier). Littérature, n. 8, 1972, pp. 3-23.

BERCHEZ, Amanda. Murilo Rubião, leitor. Dissertação (Mestrado em Teoria e História Literária) - Programa de Pós-Graduação em Teoria e História Literária da Universidade Estadual de Campinas (UNICAMP). Campinas, 2020.

BESSIÈRE, Irène: Le récit fantastique: La poétique de l'incertain. Paris: Larousse, 1973.

CAILLOIS, Roger. De la féerie à la science-fiction. In: . Anthologie du fantastique. Paris: Gallimard, 1966, pp. 7-24.

CAMARANI, Ana Luiza. A literatura fantástica: Caminhos teóricos. São Paulo: Cultura Acadêmica, 2014.

CASTEX, Pierre-Georges. Le conte fantastique en France: de Nodier à Maupassant. Paris: José Corti, 1994. 
FREUD, Sigmund. O inquietante (1919). In: . "História de uma neurose infantil" ("O homem dos lobos"), "Além do princípio do prazer" e outros textos (1917-1929). São Paulo: Companhia das Letras, 2010, pp. 329-376.

MAUPASSANT, Guy de. Adieu mystères. Le Gaulois, Paris, 1881. Disponível em: www. maupassantiana.fr/Oeuvre/ChrAdieumysteres.html. Acesso em: 15/05/2018.

MAUPASSANT, Guy de. Le fantastique. Le Gaulois, Paris, 1883. Disponível em: www. maupassantiana.fr/Oeuvre/ChrLeFantastique.html. Acesso em: 15/05/2018.

MAUPASSANT, Guy de. Oeuvres complètes de Guy de Maupassant. Paris: Louis Conard, 1902.

MAUPASSANT, Guy de. Le Horla. Édition d'André Fermigier. Paris: Gallimard (Folio Classique), 2014.

NODIER, Charles. Du fantastique en littérature. Revue de Paris, Paris, n. 17, 1830, pp. 205-226.

ROAS, David. A ameaça do fantástico: aproximações teóricas. São Paulo: UNESP, 2014.

SARTRE, Jean-Paul. Aminadab, ou o fantástico considerado como uma linguagem. In: Naify, 2005.

Situações I: críticas literárias. Tradução de Cristina Prado. São Paulo: Cosac

SCANU, Ada. Charles Nodier: Du Fantastique en littérature. Séminaire d'Histoire Littéraire: La naissance du fantastique en Europe (Histoire et Théorie). RILUNE (Revue des littératures européennes), Université de Bologne, 2004, pp. 1-26.

SCHNEIDER, Marcel. La littérature fantastique in France. Paris: Fayard, 1964.

TODOROV, Tzvetan. Introdução à literatura fantástica. Tradução de Maria Clara Corrêa Castello. São Paulo: Perspectiva, 2007.

VAX, LOUIS. L'art et le littérature fantastiques. (Deuxième édition corrigée). Paris: Presses Universitaires de France, 1963.

Recebido em: 13 fev. 2021. Aceito em: 24 mar. 2021. 